\title{
Microstructure Evolution of H62 Copper Alloy and T2 Pure Copper in Different Plastic Deformation under Tensile Loading
}

\author{
Li Lei, $\quad$ Shi Zhiming, Zhang Li \\ Inner Mongolia University of Technology, Hohhot 010051, China
}

\begin{abstract}
Uniaxial tensile tests were carried out on T2 pure copper plate and H62 copper alloy subjected to identical heat treatment. The influences of different strain states on the damage degree of both materials were analyzed. It is found that the fracture and damage of $\mathrm{T} 2$ pure copper and H62 copper alloy are closely related to their microstructure under tensile loading. The shape factor of the studied materials shows a similar variation trend with increasing strain, while shape factor for H62 copper alloy is larger than that for T2 pure copper. Evolution of relative shape factor for the studied materials shows very similar variation. In the present work, a damage variable of shape factor of grains was put forward to quantitatively describe the character of microstructure; its evolution with the plastic deformation was built-up by micro-analytical and mechanical experiments for T2 pure copper plate and H62 copper alloy. By virtue of exponential function, the normalized shape factor curves of the studied materials were fitted and the fitting equations were established, which reveals the relationship between the macroscopic deformation and microstructure of materials.
\end{abstract}

Key words: damage evolution; microstructure; plastic deformation; tensile loading; T2 pure copper and H62 copper alloy

Plastic damage of metallic materials mainly manifests as the initiation, growth and accumulation of micro-voids, whereas void damage actually means the accumulation of physical change occurring on the mesoscopic scale or even the microscopic scale. Therefore, it is important to understand the origin of void damage and to investigate the changes in microstructures such as grains, grain boundaries and phase boundaries on the mesoscopic scale upon plastic deformation $^{[1-5]}$. In association of moderate/reasonable price, copper and its alloys display excellent comprehensive physical and mechanical properties such as good thermal conductivity, good electrical conductivity, high corrosion resistance, good joint capability and good machinability. Consequently, copper and its alloys are widely used as electroconductive and thermoconductive functional materials in many fields such as electrical and electronics, electrical appliances, instrument and military industries, and are considered as one kind of indispensable fundamental materials ${ }^{[6,7]}$. Hence, numerous studies have been accomplished on copper and copper alloys ${ }^{[8-13]}$. Li et al. ${ }^{[14]}$ studied the microstructure evolution of pure copper under tension-torsion action and showed that microstructure evolutions in the overlapping and extended regions were similar. In addition, the micro-voids propagated and grew up with increasing reverse rotation. Pardis et al. ${ }^{[15]}$ established microstructure-mechanical properties relationship of pure copper under cyclic tensile extrusion. Wang et al. ${ }^{[16]}$ investigated the microstructure evolution of copper-aluminum alloy under cold rolling deformation and showed that cold rolling deformation degree greatly influences the microstructure and mechanical properties. Borkar et al. ${ }^{[17]}$ surveyed the deformation behaviors of $\mathrm{Al}-\mathrm{Si}-\mathrm{Cu}$ alloy under the tensile action, and found that eutectic silicon particles and iron-rich intermetallic compounds led to local strain concentration. This non-uniform strain distribution caused the reduction of mechanical properties. In order to describe the damage evolution, it is necessary to establish mathematical equations

Received date: December 14, 2016

Foundation item: National Natural Science Foundation of China (11002065)

Corresponding author: Li Lei, Graduate for Ph. D., Lecturer, Department of Mechanics, Inner Mongolia University of Technology, Hohhot 010051, P. R. China, E-mail: leillt@163.com

Copyright (C 2017, Northwest Institute for Nonferrous Metal Research. Published by Elsevier BV. All rights reserved. 
for damage. In this paper, uniaxial tensile tests were carried out on T2 pure copper and H62 copper alloy, and the variations in damage factors and damage degree of the two materials were analyzed under different strain states. Based on this, the damage models of T2 pure copper and H62 copper alloy were established.

\section{Definition of Microstructure Shape Factor}

In order to quantitatively describe the deformation of mesoscopic structures in metals and the evolution of grain boundaries in metallic structure, a statistical magnitude, i.e., the relative shape factor $\varphi$, is used as the characteristic parameter that describes the change in geometrical morphology of the interfacial microstructure.

To obtain a reliable damage factor, a necessity for a statistical analysis method should be given. Therefore, for the calculation of the grain boundary lengths, different microfracture within the view field were measured, and the average grain length was calculated. For selected boundaries, the effects of scratches, dark points and corrosion prints should be eliminated. In this work, ten different random fields of view were used to measure the grain boundary length. An average treatment was applied to the ten fields of view to obtain the damage factors at different strain periods.

To obtain the microstructure photographs at different plastic strains, the specimens were, respectively, loaded and then unloaded at desired strain points, which roughly distribute from yield point to the fracture.

The definition of shape factor is given as follows:

$$
\varphi=\Delta L / L_{0}=\left(L_{C}-L_{0}\right) / L_{0}
$$

Where $L_{\mathrm{C}}$ represents the total length of the grain boundary on the plane section in an arbitrary deformation state (including cracks and voids), and $L_{0}$ represents the total grain boundary length on the plane section without deformation.

Because of the random distribution of grains, $L_{\mathrm{C}}$ is measured and calculated against 5 10 of micrographs. For the uniformly deformed samples, 10 of micrographs were taken along the longitudinal symmetry axis of tensile samples. For the necking samples, 5 6 of micrographs were taken against the field around the necking transverse symmetry plane and the longitudinal axis.

The shape factor $\varphi$ varies with changing of the mesoscopic structure of materials. $\varphi$ increases in the process of damage with increasing material deformation. Thus, a relative shape factor can be used under certain damage state, $\psi$ to further describe the material damage.

$$
\psi=\varphi_{\mathrm{f}}-\varphi / \varphi_{\mathrm{f}}
$$

where $\varphi$ and $\varphi_{\mathrm{f}}$ are shape factors corresponding to $\varepsilon_{\mathrm{p}}$ and $\varepsilon_{\mathrm{f}}$, respectively. Here, $\varepsilon_{\mathrm{p}}$ is the effective plastic strain at a certain moment under external loading, and $\varepsilon_{\mathrm{f}}$ is the critical effective plastic strain when the material fractures.
In order to define damage from the mesoscopic perspective and to sensitively characterize the plastic damage degree of materials, the normalized shape factor formula is established as follows:

$$
D(\varphi)=1-\varphi_{\mathrm{f}}-\varphi / \varphi_{\mathrm{f}}
$$

where $D(\varphi)$ is the damage variable that reflects the damage degree of materials from the beginning of plastic deformation and in the processes of strengthening, necking, weakening and fracture. When $D(\varphi)=0$, the material is in an undamaged state; when $0<D(\varphi)<1$, the material is in a damaged state; when $D(\varphi)=1$, the material fractures is broken ${ }^{[18]}$.

\section{Materials and Methods}

The composition of the materials used in this work, T2 pure copper plate and H62 copper alloy, is provided in Table 1. Materials were cut into tension specimens by wire cutting (with molybdenum wire of $0.2 \mathrm{~mm}$ in diameter) method, and the specimen dimensions are shown in Fig. 1. Prior to the experiment, specimens were heated to $500{ }^{\circ} \mathrm{C}$ in the annealing furnace (OTF-1200X) and then held for $60 \mathrm{~min}$. Afterwards, the specimens were cooled in furnace to room temperature. Following heat treatment, specimens were ground and polished, and then the specimen surface was etched using the etchant $\left(5 \mathrm{~g} \mathrm{FeCl}_{3}+10 \mathrm{~mL} \mathrm{HCl}+100 \mathrm{~mL} \mathrm{H}_{2} \mathrm{O}\right)$ in order to observe the microstructure ${ }^{[19-23]}$. A MTS testing machine (MTS Landmark) was employed to carry out tensile tests, and the load was applied in the displacement mode with a loading rate of $0.2 \mathrm{~mm} / \mathrm{min}$. The testing machine was equipped with a laser extensometer (MTS Laser Extensometer LX500) to measure the displacement. In order to obtain the microscopic images at different strain stages, the specimens were loaded and unloaded independently at each strain node so as to obtain the images of specimens from the yield point to fracture. The unloaded specimens were cut along the longitudinal plane by the wire cutting, and the longitudinal plane was observed as the metallographic surface. Fracture was analyzed using a scanning electron microscope (FESEM-Hitachi High technologies, S-3400N) to obtain the fracture images. A Leica optical microscope (Leica LM/DM type) was used to obtain the metallographic images, and the microstructure was analyzed by combination of image analysis software (SISC IAS V8.0) and image processing software (the image pro plus 6.0). In order to accurately and effectively extract the grain boundary characteristics and enhance the image analysis and recognition capacity of computer, pretreatments such as noise

Table 1 Chemical composition of T2 pure copper and H62 copper (wt\%)

\begin{tabular}{cccccc}
\hline Material & $\mathrm{Cu}$ & $\mathrm{Fe}$ & $\mathrm{Zn}$ & $\mathrm{Sb}$ & $\mathrm{Pb}$ \\
\hline $\mathrm{T} 2$ & 99.97 & 0.005 & - & 0.002 & 0.004 \\
$\mathrm{H} 62$ & 62.5 & 0.11 & 37.33 & 0.005 & 0.05 \\
\hline
\end{tabular}




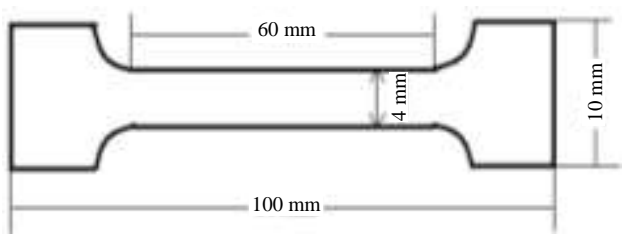

Fig. 1 Dimensions and shape of the tensile specimen

elimination and geometric correction were conducted on the metallographic images.

Fig. 2 shows the true stress-strain curves of T2 pure copper and H62 copper alloy. It can be seen that T2 pure copper shows lower tensile strength and yield strength, and larger elongation ratio and reduction of area than H62 copper alloy under the same heat-treatment (Fig.2 and Table 2).

\section{Results and Discussion}

Microstructures of the studied materials at different strain stages are shown in Fig. 3 and Fig.4. As can be seen from Fig. 3 and Fig. 4, the grains are gradually elongated along the tension direction with increasing strain. The elongation of grains becomes more significant when it reaches at the local deformation stage. Dislocation slip inside the soft copper grain in T2 pure copper is the key of the formation and growth of micro-voids. On the contrary, for the H62 copper alloy, there are relatively weak bonding positions at the grain boundaries between the two phases because of the existence of the $\alpha+\beta$ dual-phase structure. Therefore dislocation slip becomes limited in local regions. Uniform plastic deformation will stop and turn into a local deformation when the micro-voids begin to grow up ${ }^{[24-28]}$. The formation, growth and coalescence of

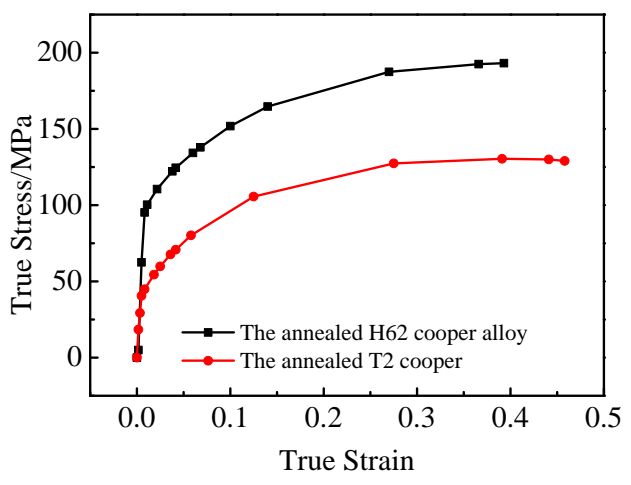

Fig. 2 True stress-strain of T2 pure copper and H62 copper alloy

Table 2 Mechanical properties of $\mathrm{T} 2$ pure copper and $\mathrm{H62}$ copper alloy

\begin{tabular}{cccc}
\multicolumn{3}{c}{ copper alloy } & \\
Material & $\begin{array}{c}\text { Elongation } \\
\text { ratio/\% }\end{array}$ & $\begin{array}{c}\text { Tensile } \\
\text { strength/MPa }\end{array}$ & $\begin{array}{c}\text { Yield } \\
\text { strength/MPa }\end{array}$ \\
\hline T2 & 48.3 & 131 & 70 \\
H62 & 41.1 & 193 & 104 \\
\hline
\end{tabular}

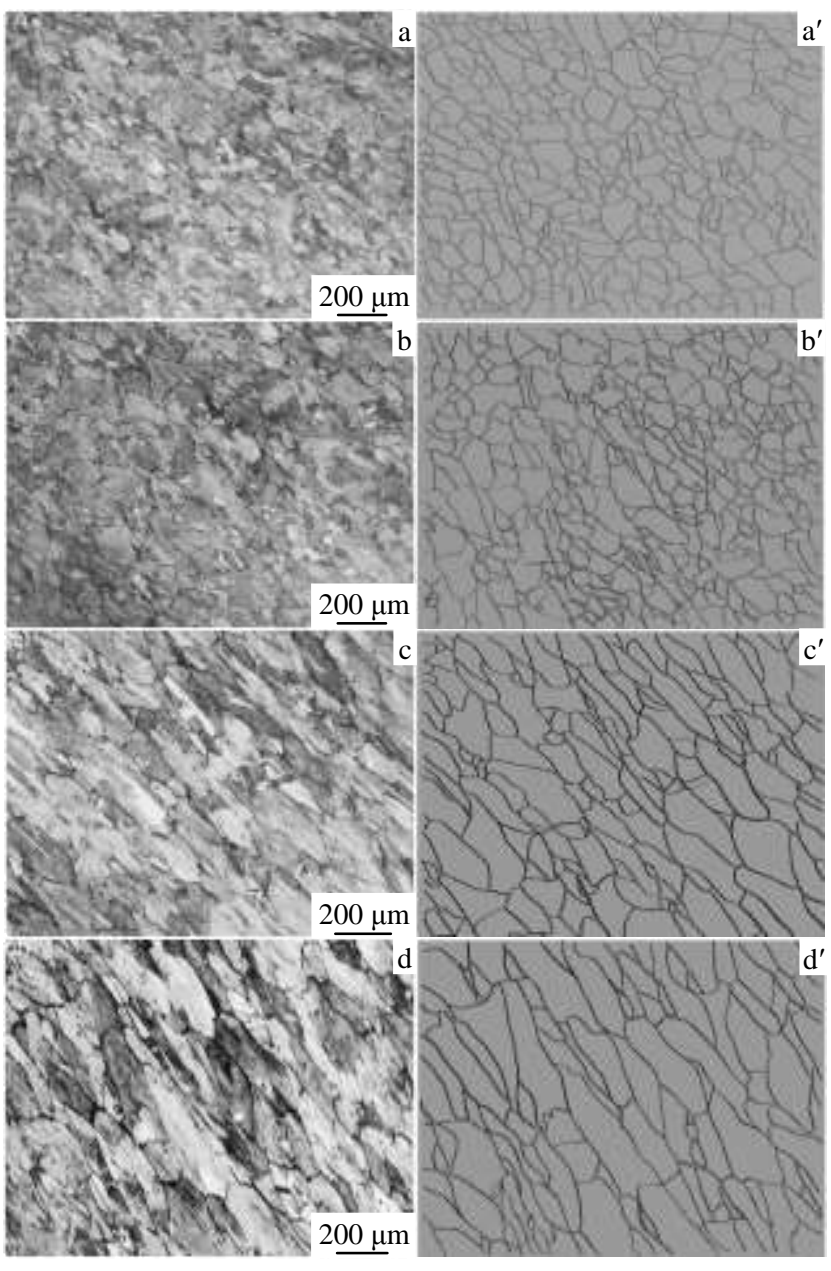

Fig. 3 Microstructures of T2 pure copper with different plastic strain: $\left(\mathrm{a}, \mathrm{a}^{\prime}\right) \varepsilon=0.112,\left(\mathrm{~b}, \mathrm{~b}^{\prime}\right) \varepsilon=0.274,\left(\mathrm{c}, \mathrm{c}^{\prime}\right) \varepsilon=0.332$, and $\left(\mathrm{d}, \mathrm{d}^{\prime}\right) \varepsilon=$ 0.457

micro-voids indicate that local deformation of the material has begun to appear, which leads to materials damage. However, different damage and failure processes can lead to different degrees of grains elongation.

Fig. 5 shows the tensile fracture micrographs of $\mathrm{T} 2$ pure copper and H62 copper alloy. As the fracture is consisted of dimples with different depths, it can be seen that the studied materials show ductile fracture. These dimples are formed mainly due to that it becomes difficult for the materials to sustain uniform deformation during the tensile process, which promotes the occurrence of stress concentration at local regions and further leads to the formation of micro-voids. As can be seen from Fig.5, T2 pure copper has better toughness than $\mathrm{H} 62$ copper alloy.

Fig. 6 shows evolution of shape factor $\varphi$ for the studied materials with respect to strain change. Similar variation trend of shape factor for both materials with the increase in strain is obtained. There is a slight difference, the shape factor for T2 pure copper increases more obviously at the late stage relative 


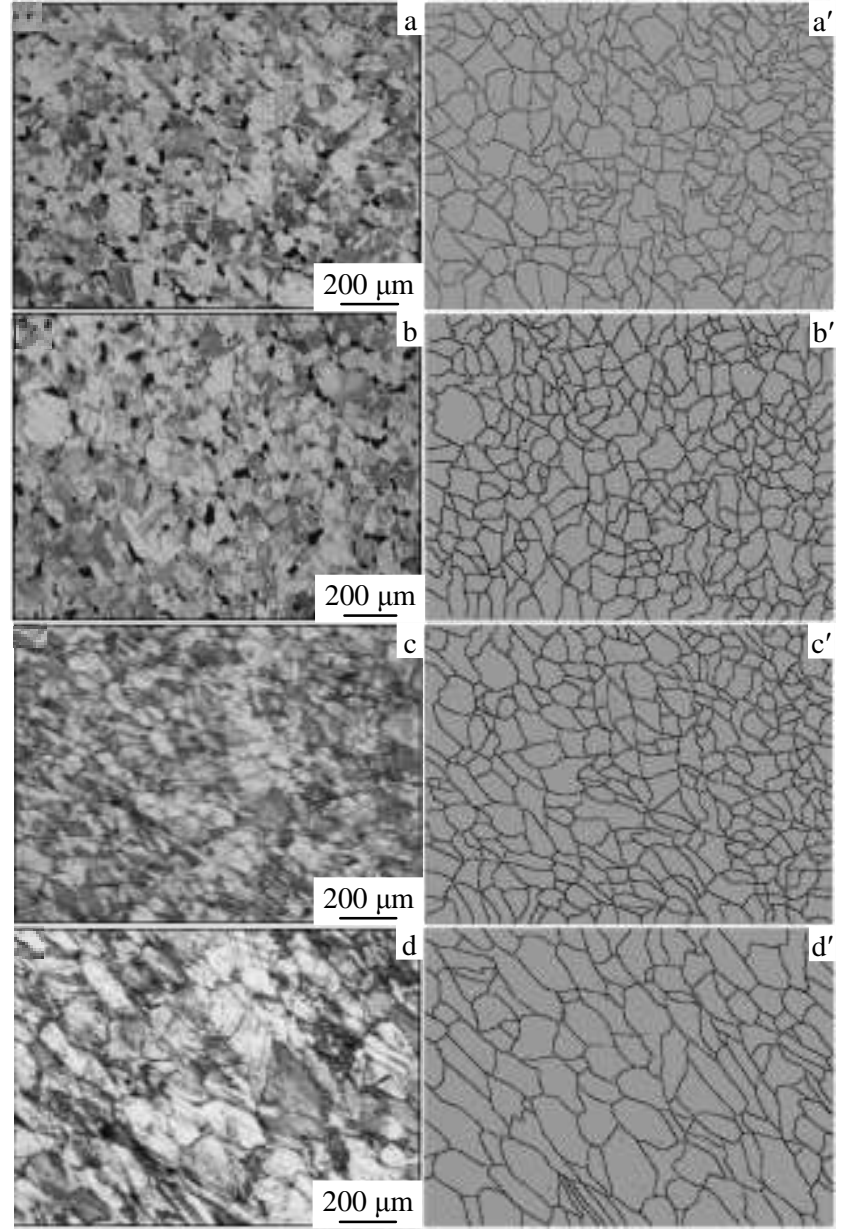

Fig. 4 Microstructures of H62 copper alloy with different plastic strain: (a, a') $\varepsilon=0.1096,\left(b, b^{\prime}\right) \varepsilon=0.178,\left(c, c^{\prime}\right) \varepsilon=0.269$, and $\left(d, d^{\prime}\right) \varepsilon=0.409$

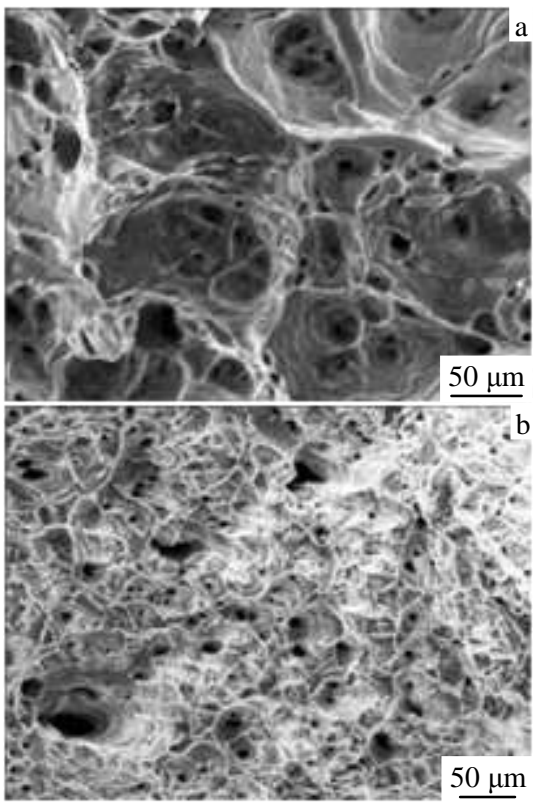

Fig.5 Tensile fracture morphologies of T2 pure copper (a) and H62 copper alloy (b)

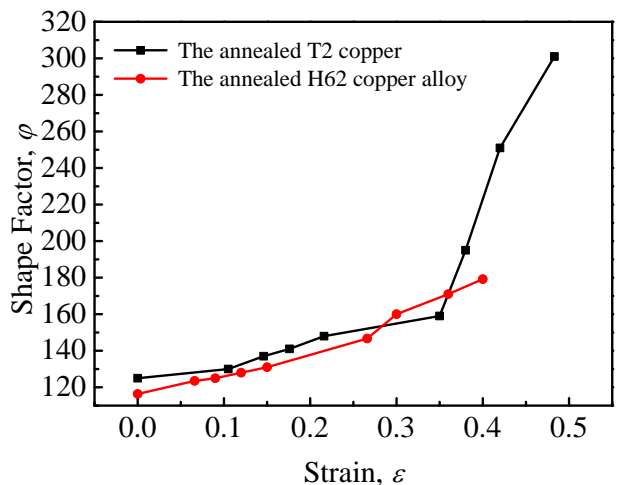

Fig. 6 Evolution of shape factor $\varphi$ for T2 pure copper and H62 copper alloy with respect to strain change

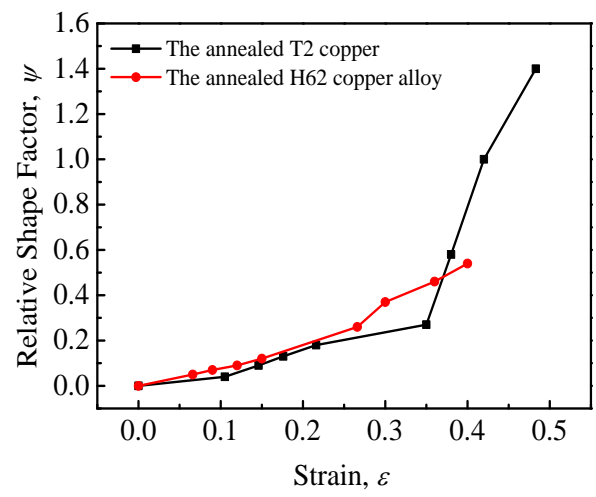

Fig.7 Evolution of relative shape factor $\psi$ for T2 pure copper and H62 copper alloy with respect to strain change

to that for H62 copper alloy. Fig.7 shows evolution curves of relative shape factor $\psi$ for both materials with respect to strain changing. As can be seen, the variation trends of the relative shape factor for both materials are very similar, and the relative increasing trends of shape factor for both materials are consistent. This is why relative shape factor is adopted in this study.

Fig. 8 shows evolution rules of normalized shape factor $D$ for both materials with respect to strain change. It can be found from the curves that H62 copper alloy enters the plastic deformation stage earlier and has a shorter plastic deformation stage than T2 pure copper. When the plastic deformation goes beyond a certain threshold, H62 copper alloy would deform and damage faster than $\mathrm{T} 2$ pure copper. This is attributed to $\alpha+\beta$ dual-phase structure of H62 copper alloy in which dislocation slip becomes limited in local small regions. Microstructure characteristics of materials can be well described by the variable of shape factor damage. In addition, the microstructure evolution with respect to strain change can reveal the relationship between macroscopic deformation and microstructure of materials. When the deformation reaches a certain value, i.e., the normalized shape factor $D$ achieves $D_{\text {c }}$ 


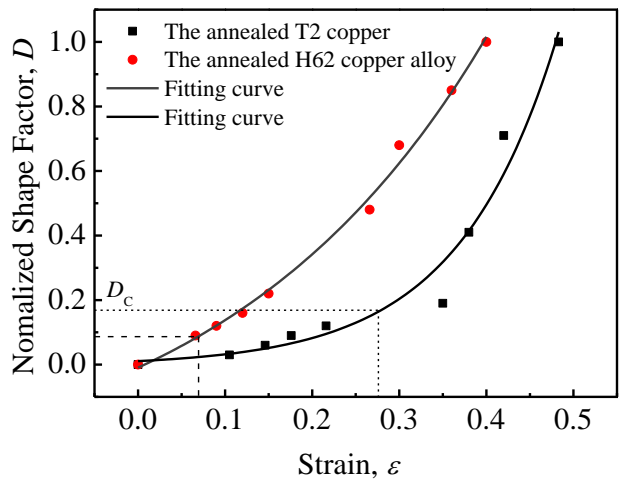

Fig. 8 Evolution of normalized shape factor $D$ for T2 pure copper and $\mathrm{H} 62$ copper alloy varying with strain change

(for T2 pure copper, $D_{\mathrm{c}}=0.1897$; for $\mathrm{H} 62$ copper alloy, $D_{\text {c }}=0.1453$ ), the damage evolution to the strain goes up steadily. This manifests as the reduction ineffective working area on the macroscopic scale and obvious deformation of grains on the mesoscopic scale.

The normalized shape factor curves of both materials are fitted using the exponential function as shown in Fig.8. The equations for the fitting curves are given below:

For H62 copper alloy, the fitting equation is expressed as follows:

$$
D=-0.39198+0.38248 \mathrm{e}^{\varepsilon / 0.03697}
$$

For T2 pure copper, the fitting equation is expressed as follows:

$$
D=-0.00399+0.0149 \mathrm{e}^{\varepsilon / 0.11389}
$$

The above fitting equations can be substituted by the following equation:

$$
D=a+b \mathrm{e}^{\varepsilon} / c
$$

where $a=-0.39198, b=0.38248, c=0.03697$ for H62 copper alloy and $a=-0.00399, b=0.0149, c=0.11389$ for T2 pure copper.

The shape factor mainly depends on the grain boundary circumference (matrix and the second phase) in the regional plane, and plastic deformation. As the strain increases, the grains are elongated, and the grain boundary circumference becomes longer accordingly. The shape factor can well reflect the microstructure characteristics of the deformation and the microstructure evolution rules of both materials. Simultaneously, shape factor is also the most suitable microscopic damage variable for describing the microstructure evolution. T2 pure copper shows a larger plastic deformation before necking compared to H62 copper alloy.

Overall, the damage evolution equations established based on the shape factor can reflect the damage and fracture rules of materials more accurately to investigate the microstructure evolution of T2 pure copper and H62 copper alloy from initial deformation to final fracture.

\section{Conclusions}

1) The shape factor of the two materials shows similar variation trend with the increase in strain. However the shape factor of H62 copper alloy is larger than that of T2 pure copper. The relative shape factor of the studied materials shows similar variation rules. By virtue of exponential function, the normalized shape factor curves of studied materials are fitted and the fitting equations are established, which reveal the relationship between the macroscopic deformation and microstructure of materials.

2) H62 copper alloy entered the plastic deformation earlier than T2 pure copper, and its plastic deformation stage was shorter than that of T2 pure copper. Beyond a certain threshold, H62 copper alloy would deform and damage faster than T2 pure copper. Damage evolution equations established based on the shape factor can more accurately reflect the damage and fracture rules of the materials.

\section{References}

1 Delale F, Erdogan F. J Appl Mech[J], 1983, 50: 609

2 Gurson A L. Fourth International Conference on Fracture[C]. Canada: University of Waterloo, 1978: 35

3 Dhar S, Dixit P M, Sethuraman R. Engineering Materials and Technology[J], 2000, 77: 335

4 Lemaitre J. Engineering Materials and Technology[J], 1985, 107: 83

5 Kachanov L M. Izv Akad Nauk USSR Otd Tekhn Nauk[J], 1958 26

6 Hornqvist M, Mortazavi N, Halvarsson M et al. Acta Materialia [J], 2015, 89: 163

7 Avettand-Fènoël M N, Racineux G, Debeugny L et al. Materials and Design[J], 2016, 98: 305

8 Xu Jie, Li Jianwei, Shan Debin et al. Materials Science \& Engineering $A[\mathrm{~J}], 2016,664: 114$

9 Fattah-alhosseini A, Imantalab O, Mazaheri Y et al. Materials Science \& Engineering A[J], 2016, 650: 8

10 Popovich A, Sufiiarov V, Polozov I et al. Materials Letters[J], 2016, 179: 38

11 Shen Jun, Pu Yayun, Yin Henggang et al. Journal of Alloys and Compounds[J], 2014, 614: 63

12 Sun Y F, Fujii H. Materials Science and Engineering A[J], 2011, 528: 5470

13 Wang Xiaofeng, Guo Mingxing, Cao Lingyong et al. Trans Nonferrous Met Soc China[J], 2015, 25: 1752

14 Li Jinghui, Li Fuguo, Hussain Mirza Zahid et al. Materials Science \& Engineering A[J], 2014, 610: 181

15 Pardis N, Chen C, Ebrahimi R et al. Materials Science \& Engineering $A[\mathrm{~J}], 2015,628: 423$ 
16 Wang Xiaofeng, Guo Mingxing, Zhang Yan et al. Journal of Alloys and Compounds[J], 2016, 657: 906

17 Borkar Hemant, Seifeddine Salem, Jarfors Anders E W. Materials and Design[J], 2015, 84: 36

18 Shi Z M, Ma H L, Li J B. Engineering Fracture Mechanics[J], 2011, 78: 503

19 Wang Wei, Zeng Weidong, Xue Chen et al. Materials Science \& Engineering $A[\mathrm{~J}]$, 2014, 603: 176

20 Prabhu T R. Archives of Civil and Mechanical Engineering[J], 2016, 16: 335

21 Luo Dan, Wang Huiyuan, Zhang Lei et al. Materials Science \& Engineering A[J], 2015, 643: 149

22 Gopi S, Manonmani K. Australian Journal of Mechanical
Engineering[J], 2013, 11: 131

23 Liu Xuefeng, Luo Jihui, Wang Xiaochen et al. Trans Nonferrous Met Soc China[J], 2015, 25: 1901

24 Huang Guoqiang, Feng Xiaomei, Shen Yifu et al. Materials and Design[J], 2016, 99: 403

25 Ran Guang, Zhou Jing'en, Wang Yongfang. Rare Metal Materials and Engineering[J], 2006, 35(10): 1620 (in Chinese)

26 Ouyang Delai, Lu Shiqiang, Cui Xia et al. Rare Metal Materials and Engineering[J], 2011, 40(2): 325 (in Chinese)

27 Kumar P Senthil, Amirthagadeswaran K S. Australian Journal of Mechanical Engineering $[\mathrm{J}], 2012,10: 9$

28 Li Pin, Zhao Bin, Xue Kemin. Chinese Journal of Solid Mechanics[J], 2015, 36: 401 (in Chinese)

\title{
H62 铜合金和 T2 纯铜不同塑性变形的微结构演变
}

\author{
李 否, 史志铭, 张 丽 \\ (内蒙古工业大学, 内蒙古 呼和浩特 010051)
}

\begin{abstract}
摘 要：对相同退火温度和相同尺寸的 T2 纯铜板和 H62 铜合金进行单向拉伸试验, 分析 2 种材料在不同应变状态下对损伤度的影响。 结果表明, $\mathrm{T} 2$ 纯铜和 H62 铜合金的断裂及损伤与其在拉伸作用下的微观组织演变密切相关, 微组织的演变对认识 2 种材料的断裂机理 非常重要。2 种材料的形状因子随着应变增大具有相似的变化趋势, 但不同的是 $\mathrm{H} 62$ 铜合金形状因子较大。2 种材料相对形状因子的变 化非常相似, 形状因子的相对增长趋势完全一致。在本研究中, 晶粒的形状因子损伤变量被用来定量描述材料的微结构特征, 通过对 2 种材料的显微分析和力学试验, 建立了材料随塑性变形的演变规律。通过指数函数对 2 种材料的归一化形状因子曲线进行了拟合, 建立 了拟合方程，揭示材料宏观变形与微结构之间的关系。
\end{abstract}

关键词: 损伤演变; 微结构; 塑性变形; 单轴拉伸; $\mathrm{T} 2$ 纯铜和 H62 铜合金

作者简介: 李 否, 男, 1980 年生, 博士生, 讲师, 内蒙古工业大学力学系, 内蒙古 呼和浩特 010051, E-mail: leillt@163.com 